\title{
Article \\ Evaluation of the Antitumour and Antiproliferative Effect of Xanthohumol-Loaded PLGA Nanoparticles on Melanoma
}

\author{
Magda Fonseca ${ }^{1,2}{ }^{\mathbb{D}}$, Ana S. Macedo ${ }^{3}$, Sofia A. Costa Lima ${ }^{3}$, Salette Reis ${ }^{3} \mathbb{D}$, Raquel Soares ${ }^{1,2}{ }^{\mathbb{D}}$ \\ and Pedro Fonte $4,5,6,7, *$ (D)
}

Citation: Fonseca, M.; Macedo, A.S.; Lima, S.A.C.; Reis, S.; Soares, R.; Fonte, P. Evaluation of the Antitumour and Antiproliferative Effect of Xanthohumol-Loaded PLGA Nanoparticles on Melanoma. Materials 2021, 14, 6421. https:// doi.org/10.3390/ma14216421

Academic Editor: Andrea Sorrentino

Received: 30 September 2021

Accepted: 21 October 2021

Published: 26 October 2021

Publisher's Note: MDPI stays neutral with regard to jurisdictional claims in published maps and institutional affiliations.

Copyright: (c) 2021 by the authors. Licensee MDPI, Basel, Switzerland. This article is an open access article distributed under the terms and conditions of the Creative Commons Attribution (CC BY) license (https:/ / creativecommons.org/licenses/by/ $4.0 /)$.
1 Department of Biomedicine, Faculty of Medicine, University of Porto, Al Prof Hernani Monteiro, 4200-319 Porto, Portugal; magdapcfonseca@zonmail.pt (M.F.); raqsoa@med.up.pt (R.S.)

2 i3S, Instituto de Investigação e Inovação em Saúde, Universidade do Porto, Rua Alfredo Allen, 208, 4200-135 Porto, Portugal

3 LAQV, REQUIMTE, Department of Chemical Sciences-Applied Chemistry Lab, Faculty of Pharmacy, University of Porto, Rua de Jorge Viterbo Ferreira 228, 4050-313 Porto, Portugal; anatmacedo@hotmail.com (A.S.M.); aclima.sofia@gmail.com (S.A.C.L.); shreis@ff.up.pt (S.R.)

4 Center for Marine Sciences (CCMAR), University of Algarve, Gambelas Campus, 8005-139 Faro, Portugal

5 Department of Chemistry and Pharmacy, Faculty of Sciences and Technology, University of Algarve, Gambelas Campus, 8005-139 Faro, Portugal

6 iBB - Institute for Bioengineering and Biosciences, Department of Bioengineering, Instituto Superior Técnico, Universidade de Lisboa, 1049-001 Lisboa, Portugal

7 Associate Laboratory i4HB-Institute for Health and Bioeconomy at Instituto Superior Técnico, Universidade de Lisboa, Av. Rovisco Pais, 1049-001 Lisboa, Portugal

* Correspondence: prfonte@ualg.pt

\begin{abstract}
Cutaneous melanoma is the deadliest type of skin cancer and current treatment is still inadequate, with low patient survival rates. The polyphenol xanthohumol has been shown to inhibit tumourigenesis and metastasization, however its physicochemical properties restrict its application. In this work, we developed PLGA nanoparticles encapsulating xanthohumol and tested its antiproliferative, antitumour, and migration effect on B16F10, malignant cutaneous melanoma, and RAW 264.7, macrophagic, mouse cell lines. PLGA nanoparticles had a size of $312 \pm 41 \mathrm{~nm}$ and a PdI of 0.259 , while achieving a xanthohumol loading of about $90 \%$. The viability study showed similar cytoxicity between the xanthohumol and xanthohumol-loaded PLGA nanoparticles at $48 \mathrm{~h}$ with the IC50 established at $10 \mu \mathrm{M}$. Similar antimigration effects were observed for free and the encapsulated xanthohumol. It was also observed that the M1 antitumor phenotype was stimulated on macrophages. The ultimate anti-melanoma effect emerges from an association between the viability, migration and macrophagic phenotype modulation. These results display the remarkable antitumour effect of the xanthohumol-loaded PLGA nanoparticles and are the first advance towards the application of a nanoformulation to deliver xanthohumol to reduce adverse effects by currently employed chemotherapeutics.
\end{abstract}

Keywords: melanoma; xanthohumol; PLGA nanoparticle; macrophage; antitumour; antiproliferative; drug delivery; cancer

\section{Introduction}

Skin cancer is the most prevalent type of malignancy in the Caucasian population of developed countries, and cutaneous melanoma is responsible for, approximately $80 \%$ of skin cancer related deaths $[1,2]$. The incidence of cutaneous melanoma has grown annually worldwide, with an increase rate of about $0.6 \%[3,4]$. Melanoma is caused by the uncontrolled division of melanocytes, $[5,6]$, and it recruits immune cells from the external environment, to integrate into the tumour microenvironment and to provide immunoprotection and faster progression and metastasis [7-10]. The macrophages are one of the 
most abundant immune cell type found in the tumour microenvironment [11-13], the tumour associated macrophages (TAM), acquiring a predominant M2 phenotype (alternative macrophage activation) or pro-tumoural phenotype [14]. In a smaller proportion, the M1 phenotype (classical macrophage activation) is present and it exerts antitumour action [15]. This phenomenon is called macrophage reverse polarization [16].

An early-stage localized cutaneous melanoma can be successfully removed by surgical treatment with a high survival rate (97-99.8\%) [17], but if not removed, it can metastasize and other conventional therapies, such as chemotherapy, radiation therapy, targeted therapy and/or immunotherapy, must be administered [18]. The personalized chemotherapies are inefficacious, because the most commonly used drugs, such as dabrafenib, trametinib, and encorafenib [19] have been found to extend remission-free period of time by only a few months, leading to the development of drug resistance and death [20-23]. Innovative strategies for treatment of cutaneous melanoma have been investigated and developed in the last decades. Phytochemicals with biological activity have become considered advantageous alternatives [24,25], mainly due to their higher safety and minimal toxicity, as is the case of polyphenols [26-29], which improve intracellular redox balance and exert a preventive activity on oxidative stress [30,31].

Xanthohumol (XN) from the hop plant (Humulus lupulus L.) has demonstrated a good bioactivity on the prevention and treatment of cutaneous melanoma, acting by inhibiting both tumourigenesis and metastasis [32]. Moreover, XN may work synergistically with the current conventional treatments to decrease the doses that often result in toxicity and severe side effects. However, XN presents poor water solubility and bioavailability, low stability, high photosensitivity and a short half-life $[33,34]$. Thus, the encapsulation of XN into nanocarriers is potentially an efficient strategy to overcome these limitations [35].

Polymeric nanoparticles are good carriers to load polyphenols due to their versatility, biocompatibility and biodegradability properties [36-38]. One of the most used polymers to produce nanoparticles is poly-lactic-co-glycolic acid (PLGA), and it has already been approved for the use in humans by the Food and Drug Administration (FDA) [39]. PLGA nanoparticles are excellent carriers to encapsulate drugs and deliver them in a sustained, controlled or even targeted manner [40-44]. An increasing interest in the design of polyphenols-loaded PLGA nanoparticles to be applied on tumour imaging [45] and targeted delivery [46-50] has been noticed in the literature. Previously, polyphenol-loaded PLGA nanoparticles showed a biphasic release, with an initial burst release to $16 \mathrm{~h}$, followed by a controlled release of up to three days [51]. This demonstrates the potential of PLGA nanocarriers to deliver polyphenols in a sustained manner, decreasing the number of administrations needed, which ultimately may improve patient treatment compliance.

The main aim of this work is to evaluate the antitumour and antiproliferative effect of XN loaded into PLGA nanoparticles in cutaneous melanoma. Therefore, a new approach in melanoma treatment is proposed. Herein, the XN will be encapsulated into nanocarriers that will be characterized and tested for efficacy in preventing the progression and metastization of tumoural melanocytes.

\section{Materials and Methods}

\subsection{Materials}

PLGA 50:50 (Purasorb ${ }^{\circledR}$ PDLG 5002A) was a gift from Corbion Purac (Amsterdam, The Netherlands) and was used to produce nanoparticles. Dichloromethane and polyvinyl alcohol (PVA, MW 89,000-98,000 Da) were from Sigma-Aldrich (St. Louis, MO, USA). The synthetic XN was from HWI Pharma Services (Rülzheim, Germany). The milli-Q water was prepared in-house. For cell culture studies, B16F10 (ATCC CRL-6475) and RAW 264.7 (ATCC TIB-71) (ATCC, Manassas, VA, USA) mouse cell lines were used. Dulbecco's modified Eagle's medium (DMEM), heat-inactivated fetal bovine serum (FBS), penicillin/streptomycin/amphotericin B were from Sigma-Aldrich (St Louis, MO, USA) and used for cell culture media. The CD86 monoclonal rabbit anti-mouse from ABclonal (Massachussets, MA, USA), and the CD206 monoclonal rat anti-mouse from ThermoFisher 
Scientific (Waltham, MA, USA) were also used. Alexa Fluor 594 conjugated goat anti-rabbit antibody and the Alexa Fluor 555 conjugated donkey anti-rat antibody were purchased from Abcam, UK.

\subsection{Production of XN-Loaded PLGA Nanoparticles}

The XN-loaded PLGA nanoparticles were produced using an adapted oil in water $(\mathrm{O} / \mathrm{W})$ emulsion technique described by Fonte et al. [43,44]. Briefly, $2 \mathrm{mg}$ of $\mathrm{XN}$ were added to $8 \mathrm{mg}$ of PLGA (50:50) and dissolved in $1 \mathrm{~mL}$ of dichloromethane, and then poured to $2 \mathrm{~mL}$ of PVA $2 \%(w / v)$. This mixture was sonicated using a Q125 Sonicator from QSonica Sonicators (Newtown, CT, USA) for $30 \mathrm{~s}$ at $70 \%$ of amplitude. Then, the dichloromethane was removed by evaporation at magnetic stirring during $3 \mathrm{~h}$. Both XN-loaded PLGA nanoparticles and unloaded PLGA nanoparticles were produced in triplicate.

\subsection{Particle Size, Polydispersity Index and Zeta Potential Characterization of XN-Loaded PLGA Nanoparticles}

The particle size and polydispersity index (PdI) were analyzed by dynamic light scattering using a Malvern ${ }^{\circledR Z}$ Zetasizer Nano ZS (Worcestershire, UK) after proper dilution with milli-Q water. The zeta potential was evaluated by the electrophoretic mobility analysis using the same equipment. All samples were analysed in triplicate at $23 \pm 2{ }^{\circ} \mathrm{C}$.

\subsection{Association Efficiency (AE) and Loading Capacity (LC) of XN}

The XN-loaded PLGA nanoparticles were centrifuged at 20,000 rpm for $20 \mathrm{~min}$ using a Centrifuge $5810 \mathrm{R}$ from Eppendorf International (Hamburg, Germany), and the supernatant was collected. The $\mathrm{XN}$ present in the supernatant was quantified by UV spectroscopy using a UV-VIS Spectrophotometer Evolution ${ }^{\circledR} 300$ from Thermo Scientific (Hertfordshire, England) at its maximum absorption wavelength $(370 \mathrm{~nm})$. The AE and LC were calculated using the following Equations:

$$
\begin{gathered}
A E=\frac{\text { Total amount of xanthohumol }- \text { Free amount of xanthohumol in the supernatant }}{\text { Total amount of xanthohumol }} \\
L C=\frac{\text { Total amount of xanthohumol }- \text { Free amount of xanthohumol in supernatant }}{\text { Total weight of nanoparticles }}
\end{gathered}
$$

\subsection{Attenuated Total Reflectance Fourier Transform Infrared Spectroscopy (ATR-FTIR)}

The obtained XN-loaded PLGA nanoparticles were freeze-dried and evaluated by ATRFTIR in a PerkinElmer ${ }^{\circledR}$ Spectrum 400 (Waltham, MA, USA) equipped with an attenuated total reflectance (ATR) device. The spectra were obtained by collecting 100 scans of each sample, between 4000 and $600 \mathrm{~cm}^{-1}$, with a resolution of $4 \mathrm{~cm}^{-1}$. The FTIR analysis was also performed for $\mathrm{XN}$ and other control samples.

\subsection{Scanning Electron Microscopy (SEM)}

The samples were previously washed with milli-Q water using a Hermle Z $32 \mathrm{HK}$ centrifuge from Hermle LaborTechnik (Wehingen, Germany) at $12,600 \times g$ for $15 \mathrm{~min}$ at $4{ }^{\circ} \mathrm{C}$. The formulations were placed on metal stubs and vacuum-coated with a layer of gold/palladium during $20 \mathrm{~s}$ with a current of $25 \mathrm{~mA}$. The SEM analysis was performed on a JSM-7001F from JEOL (Tokyo, Japan).

\subsection{Cell Culture}

B16F10 (ATCC CRL-6475) and RAW 264.7 (ATCC TIB-71) cell lines from mice were used. The B16F10 cell line was originally isolated from the cutaneous melanoma lung metastases of C57B16/J mice, and consists of high tropism metastatic cutaneous melanoma cells for lung invasion. The RAW 264.7 cell line consists of undifferentiated macrophages isolated from the tumour induced in Balb/c mice by the Abelson leukemic virus. Both cell lines were grown in DMEM supplemented with 10\% $(v / v)$ FBS and $1 \%(v / v)$ peni- 
cillin/streptomycin/amphotericin B. The cultures were kept in a $37{ }^{\circ} \mathrm{C}$ incubator in a humidified atmosphere with $5 \% \mathrm{CO}_{2}$. An extra 10\% $(v / v)$ heat-inactivated FBS volume was added to each standard $5 \mathrm{~mL}$ plate to the RAW 264.7 culture to optimize cell growth. Cellular manipulation was performed until reaching 70 to $80 \%$ confluence.

\subsection{Cell Culture Studies}

B16F10 cells were plated in 96- and 24-well plates, with an amount of $1 \times 10^{4}$ cells per well. RAW 264.7 cells were plated in 24-well plates, with an amount of $2 \times 10^{4}$ cells per well. In the case of RAW 264.7 cells, an extra volume of $10 \%$ FBS was added to each well to increase cell adhesion. The cell adhesion occurred during $24 \mathrm{~h}$ for both cell lines. $\mathrm{XN}$ was dissolved in ethanol and then added to cell culture medium at various concentrations $(2,4$, $6,8,10,20,30$, and $40 \mu \mathrm{M}), \mathrm{XN} 14 \mu \mathrm{M}$ solution, $\mathrm{XN}$-loaded PLGA nanoparticles suspension, and PLGA nanoparticles suspension with a concentration equivalent to $14 \mu \mathrm{M}$. Ethanol concentrations in cell culture were kept below $0.1 \%$ in every culture. All the treatments used DMEM without supplementation of FBS. The incubation occurred between $24 \mathrm{~h}$ and $93 \mathrm{~h}$. In the case of the RAW 264.7 incubation protocol with the 3 types of treatments described, the respective conditioned media (CM) were collected after $48 \mathrm{~h}$ of incubation and kept at $-20^{\circ} \mathrm{C}$ for analysis.

\subsection{Cell Viability Assay}

The 3-(4,5-dimethylthiazol-2-yl)-2,5-diphenyltetrazolium bromide (MTT) was added to each well, 20 and $80 \mu \mathrm{L}$ for 96 - and 24-well plates respectively, after the incubation of B16F10 cells with the treatments described in Section 2.8. The control used was the same amount of cells per well incubated in DMEM only. The incubation of the plates occurred at $37^{\circ} \mathrm{C}$ for $3 \mathrm{~h}$. The absorbance was measured at $550 \mathrm{~nm}$ and $650 \mathrm{~nm}$, and the latter wavelength corresponding to the blank assay, on ThermoElectron Corporation, Multiskan Ascent (Berverly, MA, USA) plate reader. The cell viability was determined based on the difference between the absorbances obtained at the two wavelengths used and on their variation proportional to the MTT concentration in each well, normalizing the percentage of viability to the control.

\subsection{Wound Healing Experiment}

In each well, a vertical slit with the micropipette tip was made after $24 \mathrm{~h}$ of B16F10 cells adhesion and $95 \%$ confluence, and immediately before the treatments were applied. The control used was the same amount of cells per well incubated in DMEM only. Photographs were taken of each well using an inverted Nikon Eclipse 50i microscope Nikon Europe B.V., Amsterdam, The Netherlands) with a magnitude of $200 \times$. After $48 \mathrm{~h}$ of incubation with the different solutions and suspensions, new photographs were taken of each well under similar conditions. The calculation of the percentage of migration of B16F10 cells was performed in the Image J software.

\subsection{Fluorescence Immunocytochemistry for Detection of Membrane Markers}

An immunocytochemistry assay was performed for each marker (CD86 and CD206). RAW264.7 cells were fixed with $4 \%$ paraformaldehyde solution in phosphate buffer saline (PBS) for $15 \mathrm{~min}$ at room temperature, followed by a series of 3 washes with PBS. Nonspecific binding was blocked with a blocking solution consisting of $10 \% \mathrm{FBS}, 1 \%$ bovine serum albumin (BSA) and $0.3 \mathrm{M}$ glycine in PBS for $1 \mathrm{~h}$ at room temperature and in a humidified chamber. The incubation with the CD86 monoclonal rabbit anti-mouse primary antibody A10795 and the CD206 monoclonal rat anti-mouse primary antibody MA5-16871 at 1:50 and 1:100 dilution, respectively, was performed in blocking serum, overnight at $4{ }^{\circ} \mathrm{C}$ in a humidified chamber, maintaining the negative controls with the blocking solution. Then, the incubation with secondary antibodies, namely Alexa Fluor 594 conjugated goat anti-rabbit antibody (Abcam, Cambridge, UK, ab150084) and Alexa Fluor 555 conjugated donkey anti-rat antibody ab150150, at a dilution of 1:150 and 1:200, respectively, in block- 
ing serum, was carried out for $2 \mathrm{~h}$ at room temperature in a humidified chamber. Cell nuclei were stained with 1:100 DAPI for $15 \mathrm{~min}$ at room temperature and in a humidified chamber. The mounting was made with a solution of 1:3 PBS/glycerol and the cells were observed under the "ZEISS" fluorescence microscope with the "Apotome" system and the "AxioVision" program (Carl Zeiss MicroImaging GmbH, Copenhagen, Denmark), with a magnitude of $200 \times$. Image J software was used to quantify red fluorescence for each membrane marker.

\subsection{Statistical Analysis}

The statistical analysis of the results was performed using the IBM SPSS Statistics software version 26 (IBM, Armonk, NY, USA). The non-parametric test Kruskal-Wallis for independent samples was used, considering $p=0.050$ as the level of statistical significance. Statistically significant differences are given by $p$ values $<0.050$. All quantitative values are expressed as mean \pm standard error of the mean (S.E.M.) for cell culture studies, and mean \pm standard deviation (SD) for nanoparticle characterization studies of three replicates.

\section{Results and Discussion}

\subsection{Particle Size, Polydispersity Index, Zeta Potential, AE and LC}

The particles had a size between 250-320 nm, a PdI below 0.3, and a zeta potential of approximately $-20 \mathrm{mV}$ (Table 1 ). The production method showed the formulations had great reproducibility. These results are in accordance with results previously reported, where the small size, unimodal distribution and negative surface charge result in greater particle-particle repulsion, thereby increasing the formulation stability [43]. It was observed that the PLGA nanoparticles both with and without loaded XN had similar size and PdI, demonstrating the robustness of the production method [52]. A more negative zeta potential for XN-PLGA nanoparticles was also observed, mostly due to the drug being adsorbed onto the nanoparticles surface.

Table 1. Diameter (nm), PdI, and ZP (mV), AE, and LC of the XN-loaded PLGA nanoparticles and unloaded nanoparticles $(n=3$, mean $\pm \mathrm{SD})$.

\begin{tabular}{cccccc}
\hline Formulation & Size $(\mathbf{n m})$ & PdI & ZP (mV) & AE (\%) & LC (\%) \\
\hline PLGA Np & $273 \pm 18$ & $0.285 \pm 0.015$ & $-15.4 \pm 2.1$ & - & - \\
XN-PLGA Np & $312 \pm 49$ & $0.259 \pm 0.015$ & $-18.2 \pm 1.4$ & $88.7 \pm 4.3$ & $15.9 \pm 1.1$ \\
\hline
\end{tabular}

The XN AE of the formulation was about $90 \%$ (Table I), which is a remarkable achievement when compared to recent literature reporting a AE of about $13 \%$ for XN loaded into PLGA nanoparticles [53]. Again, this shows the robustness of the nanoparticle production method. Approximately $16 \%$ of the LC was higher than the LC values reported in other studies using flavonoids encapsulated in PLGA nanoparticles, showing the feasibility of this technique and PLGA nanoparticles for the encapsulation of XN [44]. Using the developed method, hydrophobic drugs, such as $\mathrm{XN}$, do not suffer relevant leakage from the polymeric matrix to leading to high $\mathrm{XN}$ content in the nanoparticles, which is very important from the biological and industrial points of view [54].

\subsection{Interaction of XN and PLGA Nanoparticles Assessed by ATR-FTIR}

The ATR-FTIR technique was used to understand the nature of the interactions of XN and the PLGA nanoparticles. The analysis of FTIR spectra was collected for XN and PLGA to serve as controls, the PLGA nanoparticles, and the XN-loaded PLGA nanoparticles (Figure 1) after the formulations were freeze-dried. A typical peak for the PLGA between $1750-1760 \mathrm{~cm}^{-1}$ was found, characteristic of the $\mathrm{C}=\mathrm{O}$ stretching at $3000 \mathrm{~cm}^{-1}$, corresponding to the $\mathrm{C}-\mathrm{H}$ stretching [43]. The pure $\mathrm{XN}$ shows the $-\mathrm{OH}$ vibration band of the chalcone groups at $3400 \mathrm{~cm}^{-1}$, which disappears or can no longer be seen due to the band present in 
the PLGA nanoparticles spectrum at the same wavelength. The $\mathrm{C}=\mathrm{O}$ stretching spectral band at $1626 \mathrm{~cm}^{-1}$, and $-\mathrm{C}=\mathrm{C}-$ vibrations at $1545 \mathrm{~cm}^{-1}$ and $1514 \mathrm{~cm}^{-1}$ due to phenol and hydroxyl-benzoyl fractions were also observed in the XN-loaded PLGA nanoparticles [44]. This observation points out to the existence of an interaction between $\mathrm{XN}$ and polymeric nanoparticles, showing that $\mathrm{XN}$ remains associated with PLGA nanoparticles and thus efficiently loaded.

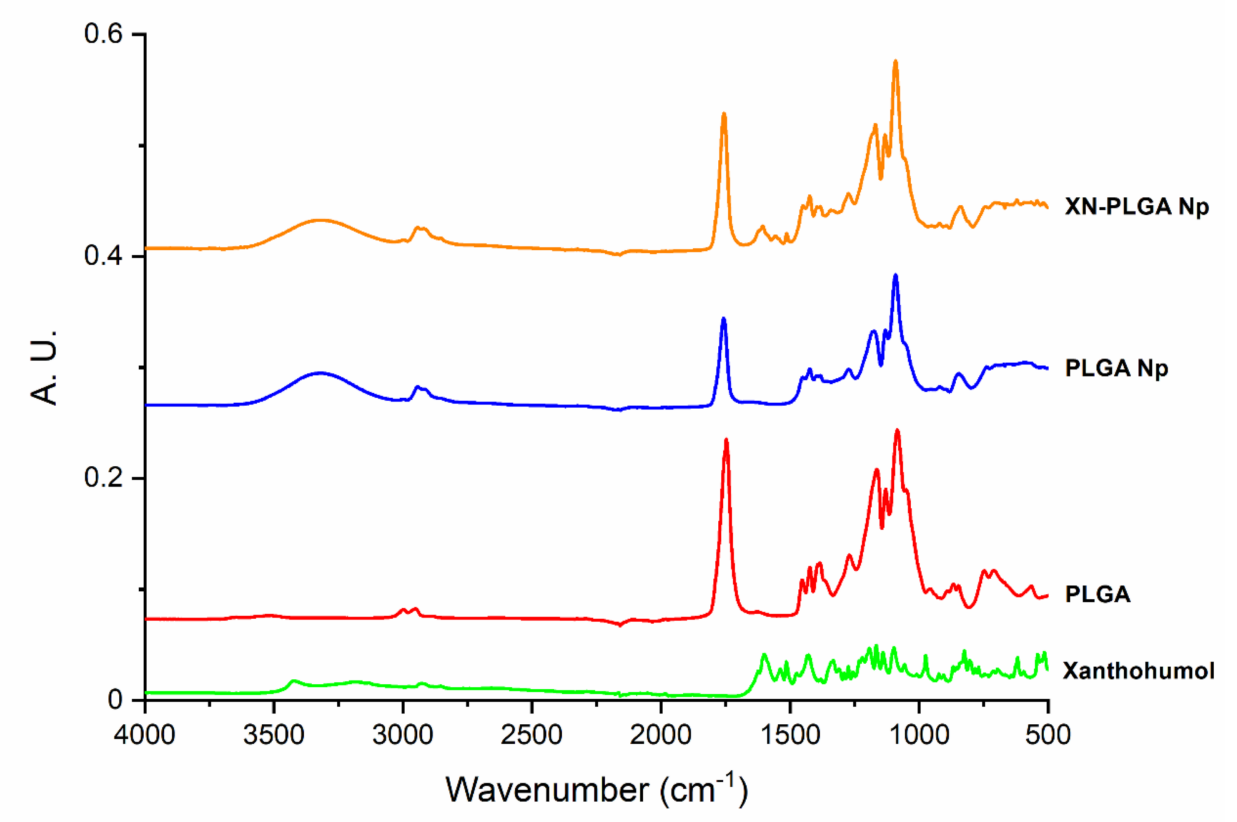

Figure 1. ATR-FTIR spectra of XN, PLGA, PLGA nanoparticles (PLGA Np), and XN-loaded PLGA nanoparticles (XN-PLGA Np).

\subsection{SEM Analysis}

The morphology of the nanoparticles was observed by SEM to evaluate the size, shape, and surface of the nanoparticles. This information is relevant to predict the stability of nanoparticles and, consequently, of the encapsulated XN. The nanoparticles were purified prior to the SEM analysis to remove the PVA, as it hides the nanoparticles upon gold/palladium coating, hindering the observation of the nanoparticle morphology. The SEM images showed that the nanoparticles had a spherical shape and smooth surface, both for the unloaded and XN-PLGA nanoparticles, showing that encapsulating XN does not affect the size, shape, and surface of the nanoparticles (Figure 2). The spherical shape and smooth surface is also characteristic of the PLGA nanoparticle matrix and encapsulating method used [43,44]. In addition, the particle size observed in the images is in accordance with the results obtained for the particle size measurements. 


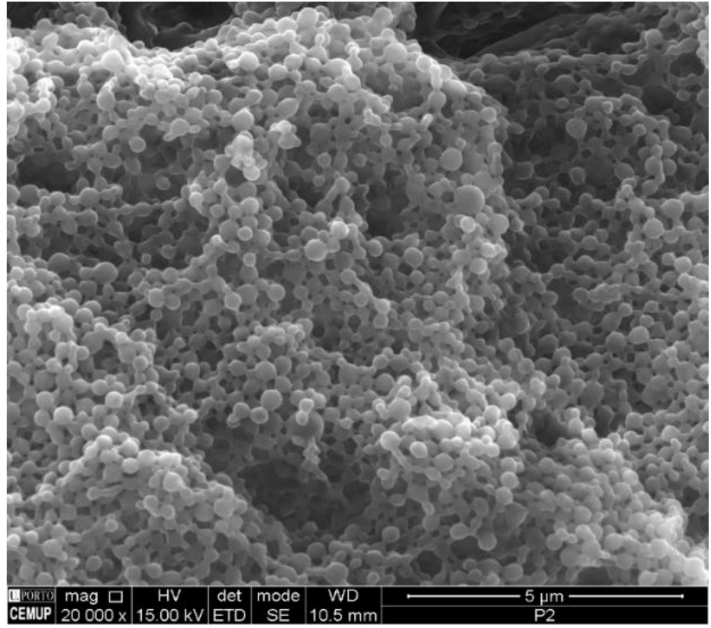

(A)

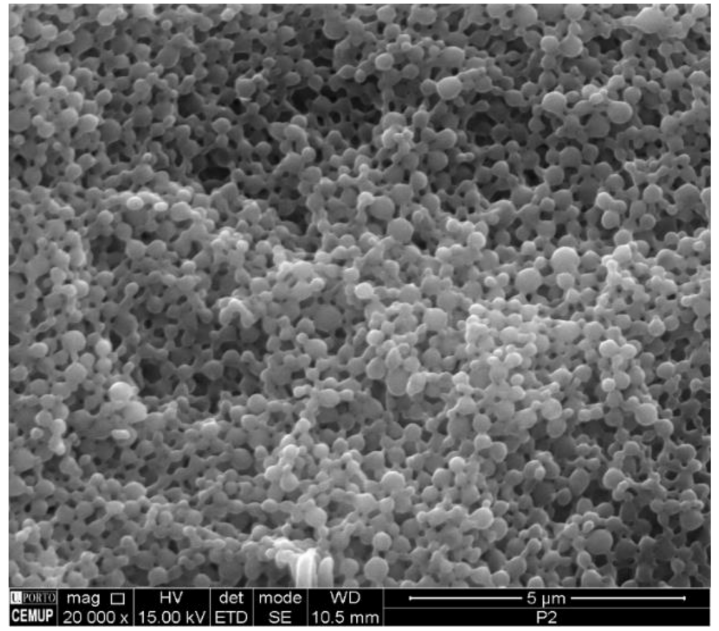

(B)

Figure 2. SEM microphotographs of unloaded nanoparticles (A) and XN-loaded nanoparticles (B) after freeze-drying $($ at $20,000 \times)$.

\subsection{B16F10 Viability Study with XN Solutions}

The use of XN as a potential cytotoxic phytochemical for cancer cells has been studied in recent years [55,56] and, in particular, for melanoma tumours $[57,58]$. The cytotoxicity of $\mathrm{XN}$ was evaluated in the B16F10 malignant cutaneous melanoma cell line using the MTT assay, with a range of concentrations between 2 and $40 \mu \mathrm{M}$ based on some previous research done by other groups [57,58]. The viability of B16F10 cells relative to control (B16F10 cells incubated with DMEM) was gradually reduced from $4 \mu \mathrm{M}$ to $10 \mu \mathrm{M}$ concentration. At the concentration of $20 \mu \mathrm{M}, \mathrm{XN}$ induced a sharp decrease of about $70 \%$ in the viability of the tumour melanocytes, maintaining the viability in the order of $10 \%$ with the remaining concentrations tested (Figure 3), with statistically significant differences relative to control $(p<0.05)$. The results suggested that $\mathrm{XN}$ is cytotoxic to the malignant cutaneous melanoma cell line B16F10 in a dose-response manner, achieving just $10 \%$ of cell viability at $20 \mu \mathrm{M}$. Interestingly, with twice of the concentration of $20 \mu \mathrm{M}$ there is not a decrease in viability, making $20 \mu \mathrm{M}$ a concentration enough and better to decrease potential side effects to healthy cells when compared with $40 \mu \mathrm{M}$. The IC50 for $\mathrm{XN}$ is, approximately, $10 \mu \mathrm{M}$ according to AAT Bioquest software for IC50 calculation.

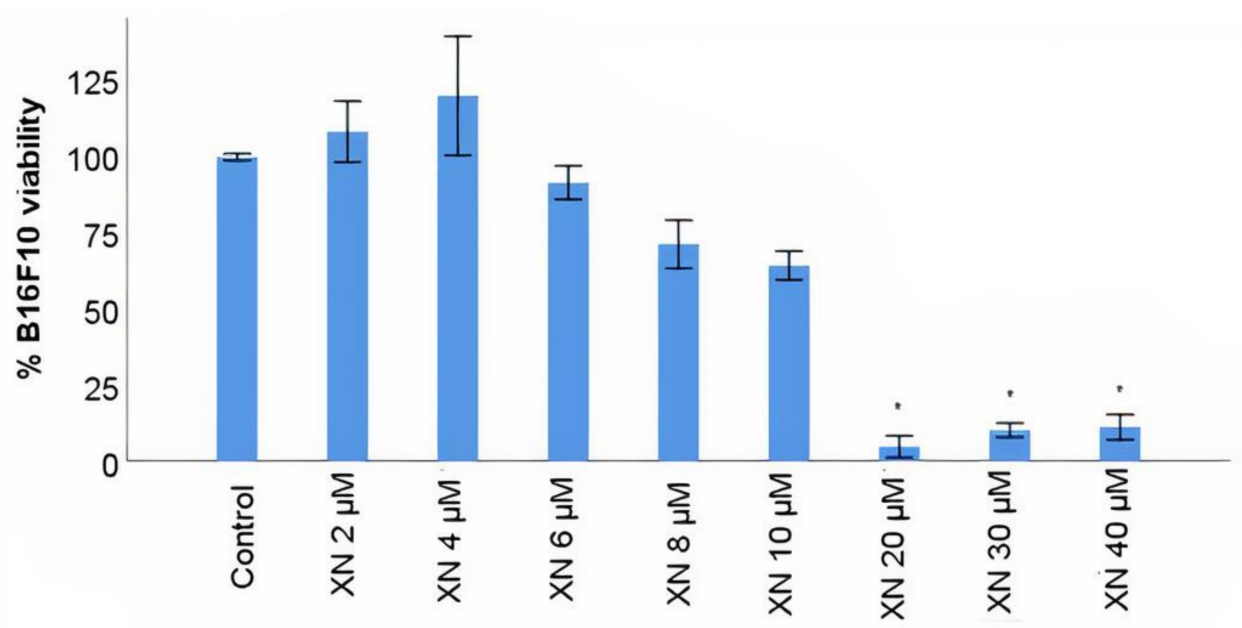

Figure 3. B16F10 viability study with solubilized $\mathrm{XN}$ in different concentrations. The control refers to B16F10 incubated with DMEM. "XN" stands for XN. B16F10 viability is expressed in mean percentage \pm S.E.M. ( $n=3$ for each treatment assay). * Statistically different at a level of $p<0.050$ in comparison with the control. 


\subsection{B16F10 Viability Study with XN-Loaded PLGA Nanoparticles Compared to XN Solubilized Form}

$\mathrm{XN}$ has physicochemical characteristics that limit its administration in the solubilized and free form [33]. The encapsulation of $\mathrm{XN}$ in nanotechnological vehicles has been tested [32], suggesting a very promising alternative for the controlled, prolonged and specific distribution of $\mathrm{XN}$ to the tumour site. PLGA is the only FDA-approved biomaterial for the production of therapeutic nanosystems [39], but the scientific literature reveals very few studies testing the antitumour efficacy of XN delivered by polymeric PLGA nanoparticles. Using the same in vitro model of malignant cutaneous melanoma, the cytotoxic action of $\mathrm{XN}$ was evaluated in B16F10 tumour melanocytes when encapsulated into PLGA polymeric nanoparticles and compared to that of $\mathrm{XN}$ in solution (non-encapsulated) by measuring the viability of B16F10 using MTT assay. The XN concentration of $14 \mu \mathrm{M}$ was used instead of $20 \mu \mathrm{M}$ (maximum cytotoxic effect, according to Figure 3), because it was closer to the IC50 $(10 \mu \mathrm{M})$. A slightly higher concentration than the IC50 was used. On one hand, a sharp reduction of B16F10 viability (between 10 and $20 \mu \mathrm{M}$ ) was desired. On the other hand, there are some studies where concentrations of $\mathrm{XN}$ up to $15 \mu \mathrm{M}$ with maximum cytotoxic effect were tested [55]. Thus, the $14 \mu \mathrm{M}$ value was defined as the $\mathrm{XN}$ concentration to be used in the following assays. According to Figure 4, the viability of B16F10 tumour melanocytes was measured in three time periods of incubation of cells with the treatments (XN solution $14 \mu \mathrm{M}-\mathrm{XN} 14 \mu \mathrm{M}$, PLGA-loaded nanoparticles with XN $14 \mu \mathrm{M}-(\mathrm{XN} 14 \mu \mathrm{M}+$ PLGA) Np-and PLGA nanoparticles-PLGA Np): at 48, 70 and $93 \mathrm{~h}$. The $93 \mathrm{~h}$ time period was used to verify the previous result. Two controls were used, one with untreated B16F10 and one with B16F10 treated with PLGA nanoparticles. PLGA nanoparticles released encapsulated XN between $48 \mathrm{~h}$ and $93 \mathrm{~h}$ of incubation of B16F10 tumour melanocytes. The cytotoxicity of $\mathrm{XN}$ to B16F10 was statistically identical to that of non-encapsulated $\mathrm{XN}$ in the same molar concentration and during the same time period (Figure 4), with statistically significant differences relative to the control (B16F10 incubated with DMEM). Regarding the temporal study, the $48 \mathrm{~h}$ time-point seems to be the most appropriate for the subsequent assays, although there are no statistically significant differences between the three time periods tested. This shorter time-point of $48 \mathrm{~h}$ ensured that the encapsulated $\mathrm{XN}$ is released from the nanosystem, with the advantage that false viability reduction-the reduction on B16F10 viability due to natural death in conditions of prolonged culture-is not considered in these results. We also observed that there are components of PLGA nanoparticles that can stimulate the increase on the viability of B16F10, with statistically significant differences relative to control (B16F10 incubated with DMEM) (Figure 4). This assay was intended to be a negative control from which the observed variation in the viability of B16F10 was not expected. The components of PLGA nanoparticles that may contribute to the increased viability observed may be the PVA and/or the PLGA polymer itself. PLGA should be pharmacologically inert according to its FDA approval for nanotechnology application. The result suggests that B16F10 cells may metabolize the biodegradable and biocompatible polymer using the resulting products to grow. This could be a mechanism of metabolic adaptation of B16F10 and, consequently, become a possible strategy of resistance to the cytotoxic effect caused by XN-loaded PLGA nanoparticles. In fact, cutaneous melanoma is a tumour that easily develops resistance to targeted therapies through mechanisms not yet fully understood. One possible test to evaluate the effect of PVA on B16F10 viability is to produce PLGA nanoparticles with another surfactant whose effect on tumour melanocyte viability is known and to compare B16F10 responses to the different surfactants. The results suggested that PLGA nanoparticles released encapsulated $\mathrm{XN}$ and the cytotoxic action of this polyphenol to B16F10 is statistically similar to that of XN in its non-encapsulated form, and that the most appropriate time period for controlled release of XN from PLGA nanoparticles is $48 \mathrm{~h}$. To quantify the amount of $\mathrm{XN}$ released from PLGA nanoparticles, release studies must be performed. 


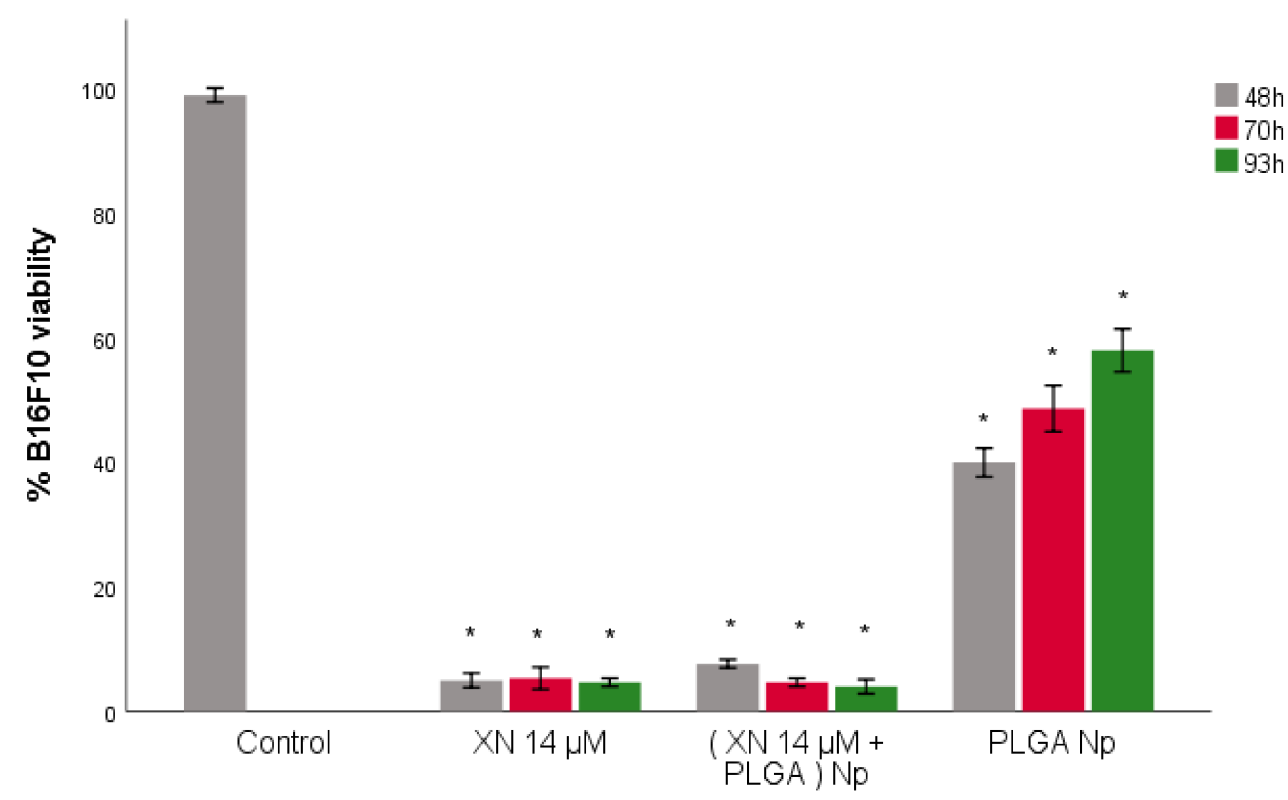

Figure 4. B16F10 viability assay with XN-loaded PLGA nanoparticles compared to XN solubilized form. The control refers to B16F10 incubated with DMEM. "XN", "Np" and "PLGA" stands for XN, nanoparticles and poly-lactic-co-glycolic acid, respectively. B16F10 viability is expressed in mean percentage \pm S.E.M. ( $n=3$ for each treatment assay). ${ }^{*}$ Statistically different at a level of $p<0.050$ in comparison with the control.

\subsection{B16F10 Migration Study with XN-Loaded PLGA Nanoparticles Compared to XN Solubilized Form}

The ability of $\mathrm{XN}$ to inhibit the migration of B16F10 tumour melanocytes, in the free and in the nanoencapsulated form, at a concentration of $14 \mu \mathrm{M}$ and at the time period of $48 \mathrm{~h}$ of incubation of B16F10 with the treatments, was evaluated by the "Wound Healing" assay (Figure 5). Previous in vitro assays to evaluate the ability of $\mathrm{XN}$ to inhibit migration of cells from different tumour lines have revealed that this polyphenol may be used on the prevention of metastisation, because it suppresses the migratory phenotype of diverse tumour cell types $[59,60]$. Based on these results, the next step was to understand whether the same effect occurs with the malignant cutaneous melanoma cell line B16F10, as reported. Since the evaluation of the therapeutic and preventive potential of an XN nanosystem is the main goal of this research, this assay also tested nanoencapsulated XN. The concentration value and incubation time used were obtained from the assays previously performed. $\mathrm{XN}$ inhibited the migration of B16F10 tumour melanocytes, either in the non-encapsulated and in the encapsulated form by PLGA nanoparticles (Figure 5), with no statistically significant differences between these two XN formulations (Figure 5B). Regarding the control (B16F10 incubated with DMEM), there are statistically significant differences in the inhibitory activity of these two forms of $\mathrm{XN}$, as shown in Figure 6. We also observed that there are components of PLGA nanoparticles non-loaded with XN that can stimulate an increased migration of B16F10 (Figure 5B). This result was similar to that obtained from the viability assay and it was also unexpected. The same discussion can be approached, as well as the future research perspectives about studying the stimulatory effect on migration caused by PLGA and/or PVA. The results suggest that PLGA nanoparticles are efficient vehicles of $\mathrm{XN}$, favoring their inhibitory action on the migration of B16F10 tumour melanocytes, in a statistically identical way to $\mathrm{XN}$ in its free form. 


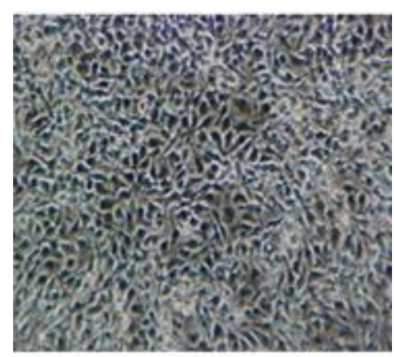

Control

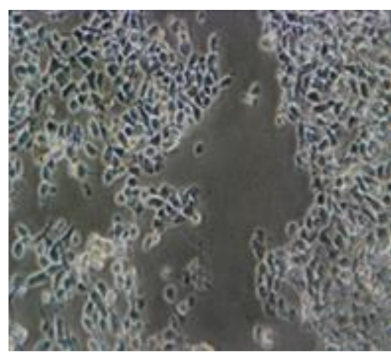

PLGA Np

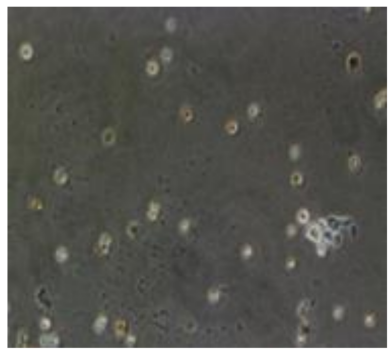

$\mathrm{XN} 14 \mu \mathrm{M}$

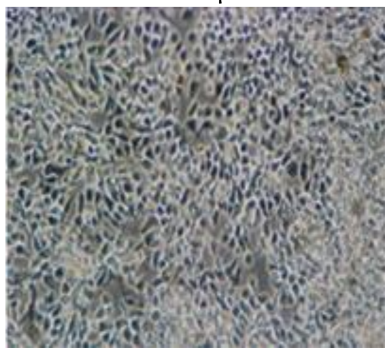

(XN $14 \mu \mathrm{M}+$ PLGA) Np

(A)

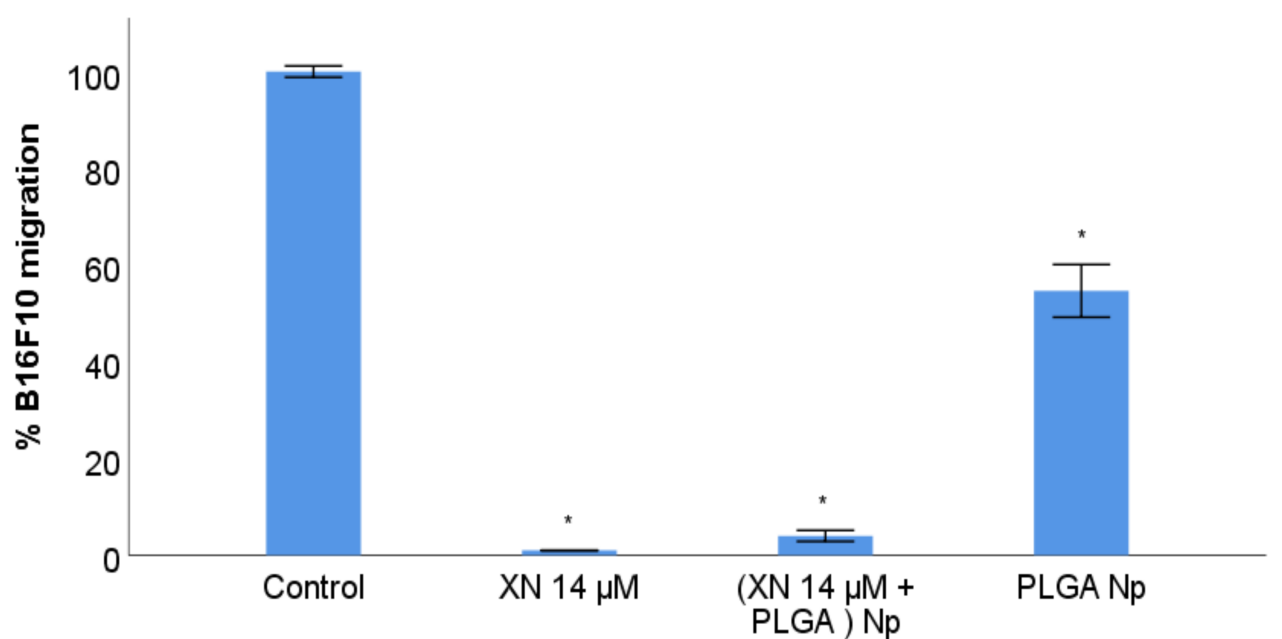

(B)

Figure 5. B16F10 Wound Healing assay with XN-loaded PLGA nanoparticles compared to XN solubilized form after $24 \mathrm{~h}$ treatment. The control refers to injury assay of B16F10 cells incubated with DMEM. "XN", “Np", and "PLGA" stands for XN, nanoparticles and poly-lactic-co-glycolic acid, respectively. (A) Representative inverted optical microscopic images, 200×. (B) Bars represent B16F10 cells migration towards the injured space. B16F10 migration is expressed in mean percentage \pm S.E.M. ( $n=3$ for each treatment assay). * Statistically different at a level of $p<0.050$ in comparison with the control. 


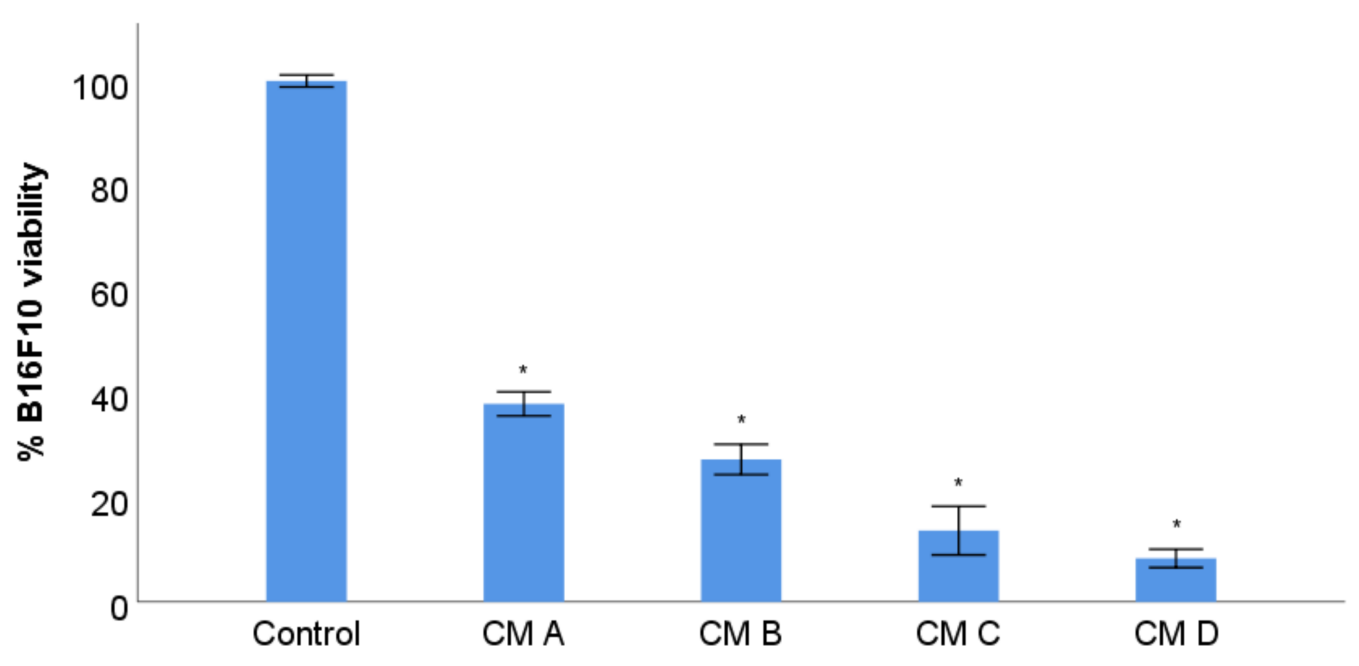

Figure 6. B16F10 viability study with CM from stimulation of RAW 264.7 with XN-loaded PLGA nanoparticles and XN solubilized form. The control refers to B16F10 incubated with DMEM. B16F10 cells treated with: CM from RAW 264.7 incubated with DMEM (A), CM from RAW 264.7 incubated with XN solution $14 \mu \mathrm{M}$ (B), CM from RAW 264.7 incubated with XN-loaded PLGA nanoparticles (C), CM from RAW 264.7 incubated with PLGA nanoparticles (D). B16F10 viability is expressed in mean percentage \pm S.E.M. $(n=3$ for each treatment assay). The experiment was repeated three times. * $p<0.050$ in comparison with the control.

\subsection{B16F10 Viability Study with Conditioned Media from Stimulation of RAW 264.7 with XN-Loaded PLGA Nanoparticles and XN Solubilized Form}

The tumour microenvironment plays a crucial role in cancer progression. Understanding the interactions between tumour cells and the surrounding microenvironmental cells (immune, endothelial, epithelial, etc), as well as the interactions with nonliving elements such as the extracellular matrix [61,62] allows us to define new therapeutic and cancer prevention strategies [63]. Thus, it was essential to investigate the biological action of XN on macrophages, a type of immune cells very often present in the microenvironment of any tumour [64], along with studying the direct effect of XN on viability and migratory capacity of tumour melanocytes. Previous studies suggested that XN has a diverse biological action on macrophages under pathological conditions other than cancer $[65,66]$. Few reports have focused on the interaction between $\mathrm{XN}$ and macrophages in cancer [67]. Therefore, the investigation performed on malignant cutaneous melanoma becomes a pertinent innovation. An inherent biological function of macrophages is their ability to change their phenotype polarization depending on whether external stimuli are more or less inflammatory, acquiring specific membrane receptors characteristic of an anti-tumour (M1) or pro-tumour (M2) phenotype, as noted above. Based on this evidence, the next step was to evaluate the immunomodulatory activity of $\mathrm{XN}$ in the non-encapsulated and in the nano-encapsulated form, on the RAW 264.7 macrophage cell line, by quantifying the viability of the B16F10 tumour melanocytes using the MTT assay. B16F10 cells were treated with CM from RAW 264.7 cultures incubated with XN solution $14 \mu \mathrm{M}$ and suspensions of XN-loaded PLGA nanoparticles and non-loaded PLGA nanoparticles.

A higher reduction on the viability of B16F10 tumour melanocytes in the presence of CM from RAW 264.7 treated with non-encapsulated and nano-encapsulated XN, relative to the absence of treatments, was observed, as shown in Figure 6, implying that the macrophage phenotype modulation is classic anti-tumour M1. PLGA nanoparticles stimulated a M1 macrophage phenotype, as well. (Figure 6). The results suggest that RAW 264.7 macrophages are a biological target for XN in the non-encapsulated and in the encapsulated form of PLGA-loaded nanoparticles, exhibiting a predominant M1 or antitumour phenotype. 
It should be noted that the results obtained should take into account the effect of solubilized XN on B16F10 in the CM from RAW 264.7 that was previously treated with $\mathrm{XN}$ solution and XN-loaded PLGA nanoparticle suspension, which was found to be toxic to these tumour cells. Therefore, the observed decrease in B16F10 viability may result from the association between the direct cytotoxic effect of solubilized $\mathrm{XN}$ and the antitumour effect promoted by RAW 264.7 stimulated with the mentioned treatments. This additive or synergistic effect simulates what happens in vivo, as $\mathrm{XN}$ will act simultaneously on the tumour cells of cutaneous melanoma and on the microenvironment components, namely macrophages.

\subsection{RAW 264.7 Phenotype Membrane Markers Study with Previous Stimulation with XN} Solubilized Form and Non-Encapsulated PLGA Nanoparticles

To examine whether free and encapsulated $\mathrm{XN}$ induced a macrophage phenotypic switch, immunofluorescence was performed to quantify the CD86 (M1 polarization) and CD206 (M2 polarization) macrophage membrane markers of RAW 264.7 treated with non-encapsulated XN and PLGA nanoparticles. XN and PLGA nanoparticles have a macrophage phenotype modulation capacity per se (Figure 7). They induce M2 and M1 polarization phenotypes on RAW 264.7, respectively (Figure 7), with statistically significant differences between both phenotypes. This $\mathrm{XN}$-induced M2 polarization is compatible with the anti-inflammatory activity of this polyphenol [68-70]. The M1-type polarization observed for free PLGA nanoparticles may be directly induced by PLGA and/or PVA, although only a few studies support this hypothesis [71]. The highest reduction in B16F10 melanoma cell viability observed upon incubation with conditioned medium from PLGA nanoparticles-treated RAW 264.7 can be explained by the previous findings that PLGA nanoparticles induce a switch towards anti-tumor M1 phenotype. The antitumor phenotype of these cells may thereby reduce B16F10 melanoma cell viability.

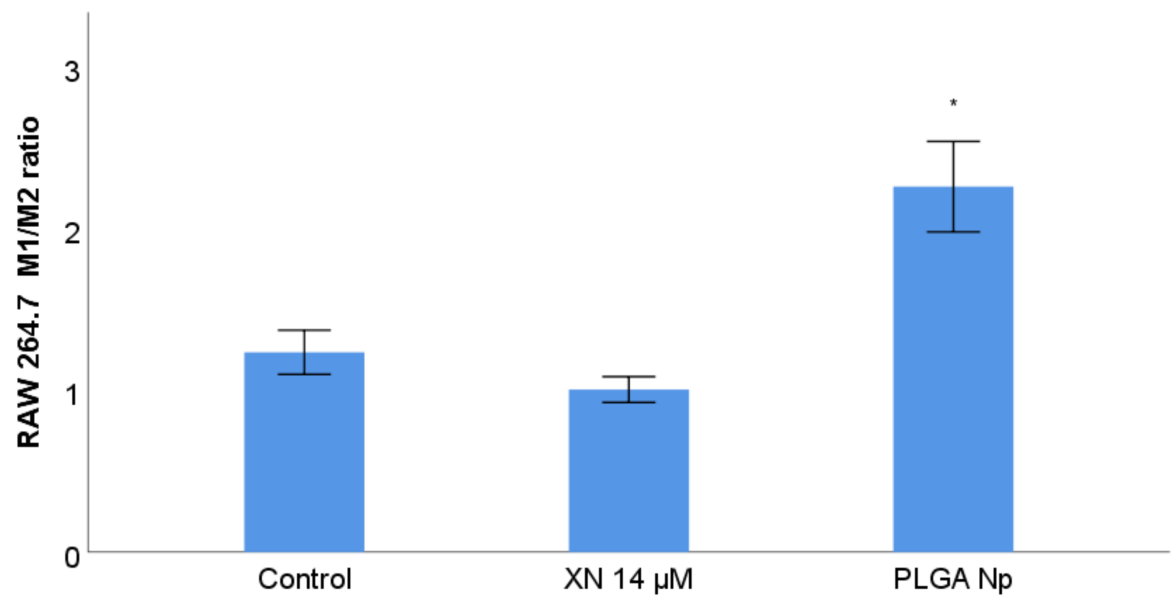

Figure 7. RAW 264.7 phenotype membrane markers study with previous stimulation with XN solubilized form and PLGA nanoparticles. The control refers to RAW 264.7 incubated with DMEM. "XN", "Np" and "PLGA" stands for XN, nanoparticles and poly-lactic-co-glycolic acid, respectively. M1 represents an anti-tumour phenotype and $\mathrm{M} 2$ a pro-tumour phenotype. M1/M2 ratio values are expressed as mean \pm S.E.M. $\left(n=6\right.$ for each treatment assay). ${ }^{*}$ Statistically different at a level of $p<0.050$ in comparison with the control.

Comparing the results of this assay with those of the previous one, it is suggested, on the one hand, that $\mathrm{XN}$ has a more significant cytotoxic action than its macrophage immunomodulatory effect at the tested concentration of $14 \mu \mathrm{M}$, and, on the other hand, that PLGA polymeric nanoparticles have a more significant macrophage immunomodulation activity than their observed cytostimulant effect, for a tested concentration of nanoparticles equivalent to $14 \mu \mathrm{M}$. The total effect of XN-loaded PLGA nanoparticles on 
B16F10, in the presence of macrophages stimulated by this nanosystem, is the result of the association between the action on cell viability and the immunomodulatory action, both exerted by the individual components of the nanosystem. It was essential to design the in vitro test performed to understand all the biological activities tested in order to optimize the formulation of the produced nanosystem. The optimization will minimize the pro-tumour effect of macrophages of the tumour microenvironment, so that the action of nanoparticles loaded with $\mathrm{XN}$ can be a therapeutic adjuvant against malignant cutaneous melanoma. Probably the same components that induce a macrophage M1 phenotype are those that cause increased viability of tumour melanocytes when PLGA nanoparticles are tested. To minimize this increase in melanoma viability, and the selection of one that does not cause tumour growth and maintains or enhances M1 or antitumour macrophage modulation. Further testing should be done to test new nanoparticle formulations and new encapsulation methods for $\mathrm{XN}$ to optimize the interaction between these nanosystems, B16F10 tumour melanocytes and RAW 264.7 macrophages in novel in vitro models. To maximize the cytotoxic effect of the nanoparticles used in this study, their surface may be functionalized to make them selective for the melanoma site.

\section{Conclusions}

The $\mathrm{XN}$ was successfully encapsulated in PLGA nanoparticles, and the formulation displayed an antitumour effect by presenting cytoxicity and inhibiting the proliferation and migration of the B16F10 malignant cutaneous melanoma cell line. These results indicate that XN delivered by PLGA nanoparticles is an alternative with high therapeutic and preventive potential against malignant cutaneous melanoma. However, the underlying mechanisms of $\mathrm{XN}$ and $\mathrm{XN}$-loaded PLGA nanoparticles are still unknown. A pertinent and interesting future approach will be to perform the same tests in in vitro and in vivo models simulating pathological metabolic conditions such as obesity. Precision medicine has gained relevance in the scientific community and extending studies on nanotechnology to metabolic risk groups is very valuable to design personalized antitumour therapies.

Author Contributions: Conceptualization, R.S. and P.F.; methodology, S.A.C.L. and A.S.M.; software, M.F.; validation, S.R.; formal analysis, P.F.; investigation, M.F.; resources, R.S. and P.F.; data curation, A.S.M.; writing-original draft preparation, M.F. and A.S.M.; writing—review and editing, S.A.C.L., S.R., R.S. and P.F.; supervision, R.S. and P.F.; project administration, P.F.; funding acquisition, P.F. All authors have read and agreed to the published version of the manuscript.

Funding: This work was financed by FEDER-Fundo Europeu de Desenvolvimento Regional funds through the COMPETE 2020-Operational Programme for Competitiveness and Internationalization (POCI), and by Portuguese funds through Fundação para a Ciência e a Tecnologia (FCT) in the framework of the project POCI-01-0145-FEDER-032610—PTDC/MEC-DER/32610/2017. It was also supported by national funds from FCT in the scope of the projects UIDB/50006/2020 of the Associate Laboratory LAQV, REQUIMTE, UIDB/04326/2020 of the Research Unit Center for Marine Sciences-CCMAR, and UIDB/04565/2020 and UIDP/04565/2020 of the Research Unit Institute for Bioengineering and Biosciences- iBB, and the project LA/P/0140/2020 of the Associate Laboratory Institute for Health and Bioeconomy-4HB.

Institutional Review Board Statement: Not applicable.

Informed Consent Statement: Not applicable.

Data Availability Statement: Not applicable.

Acknowledgments: The authors would like to thank Fundação para a Ciência e Tecnologia (FCT), Portugal for funding, and all the institutions involved in the work.

Conflicts of Interest: The authors declare no conflict of interest. 


\section{References}

1. Prado, G.; Svoboda, R.M.; Rigel, D.R. What's New in Melanoma. Dermatol. Clin. 2019, 37, 159-168.

2. Apalla, Z.; Nashan, D.; Weller, R.; Castellsagué, X. Skin cancer: Epidemiology, disease burden, pathophysiology, diagnosis, and therapeutic approaches. Dermatol. Ther. 2017, 7, 5-19. [CrossRef] [PubMed]

3. Carr, S.; Smith, C.; Wernberg, J. Epidemiology and risk factors of melanoma. Surg. Clin. North Am. 2020, 100, 1-12. [CrossRef] [PubMed]

4. Che, G.; Huang, B.; Xie, Z.; Zhao, J.; Yan, Y.; Wu, J.; Sun, H.; Ma, H. Trends in incidence and survival in patients with melanoma, 1974-2013. Am. J. Cancer Res. 2019, 9, 1396-1414.

5. Siegel, R.L.; Miller, K.D.; Jemal, A. Cancer statistics. CA Cancer J. Clin. 2016, 66, 7-30. [CrossRef]

6. Miller, K.; Siegel, R.; Lin, C.; Mariotto, A.; Kramer, J.; Rowland, J.; Stein, K.D.; Alteri, R.; Jemal, A. Cancer treatment and survivorship statistics. CA Cancer J. Clin. 2016, 66, 271-289. [CrossRef]

7. Liu, C.; Steen, C.; Newman, A. Computational approaches for characterizing the tumor immune microenvironment. Immunology 2019, 158, 70-84. [CrossRef] [PubMed]

8. Tuccitto, A.; Shahaj, E.; Vergani, E.; Ferro, S.; Huber, V.; Rodolfo, M.; Castelli, C.; Rivoltini, L.; Vallacchi, V. Immunosuppressive circuits in tumor microenvironment and their influence on cancer treatment efficacy. Virchows Arch. 2019, 474, 407-420. [CrossRef] [PubMed]

9. Butturini, E.; Carcereri de Prati, A.; Boriero, D.; Mariotto, S. Tumor Dormancy and Interplay with Hypoxic Tumor Microenvironment. Int. J. Mol. Sci. 2019, 20, 4305. [CrossRef] [PubMed]

10. Hinshaw, D.S.; Shevde, L.A. The Tumor Microenvironment Innately Modulates Cancer Progression. Cancer Res. 2019, 79, 4557-4566. [CrossRef] [PubMed]

11. Wang, J.; Li, D.; Cang, H.; Guo, B. Crosstalk between cancer and immune cells: Role of tumor-associated macrophages in the tumor microenvironment. Cancer Med. 2019, 8, 4709-4721. [CrossRef]

12. Larionova, I.; Cherdyntseva, N.; Liu, T.; Patysheva, M.; Rakina, M.; Kzhyshkowska, J. Interaction of tumor-associated macrophages and cancer chemotherapy. Oncoimmunology 2019, 8, 1596004. [CrossRef]

13. Salmaninejad, A.; Valilou, S.; Soltani, A.; Ahmadi, S.; Abarghan, Y.; Rosengren, R.; Sahebkar, A. Tumor-associated macrophages: Role in cancer development and therapeutic implications. Cell. Oncol. 2019, 42, 591-608. [CrossRef]

14. Wang, H.; Yang, L.; Wang, D.; Zhang, Q.; Zhang, L. Pro-tumor activities of macrophages in the progression of melanoma. Hum. Vaccin. Immunother. 2017, 13, 1556-1562. [CrossRef] [PubMed]

15. Ley, K.; Pramod, A.B.; Croft, M.; Ravichandran, K.S.; Ting, J.P. How mouse macrophages sense what is going on. Front. Immunol. 2016, 7, 204. [CrossRef] [PubMed]

16. Yuan, R.; Li, S.; Geng, H.; Wang, X.; Guan, Q.; Li, X.; Ren, C.; Yuan, X. Reversing the polarization of tumor-associated macrophages inhibits tumor metastasis. Int. Immunopharmacol. 2017, 49, 30-37. [CrossRef] [PubMed]

17. Zitelli, J.A.; Mohs, F.E.; Larson, P.; Snow, S. Mohs micrographic surgery for melanoma. Dermatol. Clin. 1989, 7, 833-843. [CrossRef]

18. Boyle, G. Therapy for metastatic melanoma: An overview and update. Expert. Rev. Anticancer. Ther. 2011, 11, 725-737. [CrossRef]

19. Institute Report. Global Oncology Trends 2018-Innovation, Expansion and Disruption. The IQVIA Institute. Available online: https://www.iqvia.com/insights/the-iqvia-institute/reports/global-oncology-trends-2018 (accessed on 1 October 2021).

20. Broman, K.K.; Dossett, L.A.; Sun, J.; Eroglu, Z.; Zager, J.S. Update on BRAF and MEK inhibition for treatment of melanoma in metastatic, unresectable, and adjuvant settings. Expert Opin. Drug. Saf. 2019, 18, 381-392. [CrossRef] [PubMed]

21. Rose, A. Encorafenib and binimetinib for the treatment of BRAF V600E/K-mutated melanoma. Drugs Today 2019, 55, 247-264. [CrossRef]

22. Arozarena, I.; Wellbrock, C. Phenotype plasticity as enabler of melanoma progression and therapy resistance. Nat. Rev. Cancer 2019, 19, 377-391. [CrossRef] [PubMed]

23. Robert, C.; Grob, J.J.; Stroyakovskiy, D.; Karaszewska, B.; Hauschild, A.; Levchenko, E.; Sileni, V.C.; Schachter, J.; Garbe, C.; Bondarenko, I.; et al. Five-year outcomes with dabrafenib plus trametinib in metastatic melanoma. N. Engl. J. Med. 2019, 381, 626-636. [CrossRef]

24. Singh, V.K.; Arora, D.; Ansari, M.I.; Sharma, P.K. Phytochemicals based chemopreventive and chemotherapeutic strategies and modern technologies to overcome limitations for better clinical applications. Phytother. Res. 2019, 33, 3064-3089.

25. Arora, I.; Sharma, M.; Tollefsbol, T.O. Combinatorial Epigenetics Impact of Polyphenols and Phytochemicals in Cancer Prevention and Therapy. Int. J. Mol. Sci. 2019, 20, 4567. [CrossRef]

26. Heenatigala Palliyage, G.; Singh, S.; Ashby, C.R.; Tiwari, A.K.; Chauhan, H. Pharmaceutical Topical Delivery of Poorly Soluble Polyphenols: Potential Role in Prevention and Treatment of Melanoma. AAPS PharmSciTech 2019, 20, 250. [CrossRef] [PubMed]

27. Sajadimajd, S.; Bahramsoltani, R.; Iranpanah, A.; Patra, J.K.; Das, G.; Gouda, S.; Rahimi, R.; Rezaeiamiri, E.; Cao, H.; Giampieri, F.; et al. Advances on natural polyphenols as anticancer agents for skin cancer. Pharmacol. Res. 2020, 151, 104584. [CrossRef]

28. Ravikumar, P.; Katariya, M.; Patil, S.; Tatke, P.; Pillai, R. Skin delivery of resveratrol encapsulated lipidic formulation for melanoma chemoprevention. J. Microencapsul. 2019, 36, 535-551. [CrossRef]

29. Prieto, K.; Cao, Y.; Mohamed, E.; Trillo-Tinoco, J.; Sierra, R.A.; Urueña, C.; Sandoval, T.A.; Fiorentino, S.; Rodriguez, P.C.; Barreto, A. Polyphenol-rich extract induces apoptosis with immunogenic markers in melanoma cells through the ER stress-associated kinase PERK. Cell Death Discov. 2019, 5, 134. [CrossRef] [PubMed] 
30. Afaq, F.; Katiyar, S. Polyphenols: Skin photoprotection and inhibition of photocarcinogenesis. Mini Rev. Med. Chem. 2011, 11, 1200-1215. [PubMed]

31. Strickland, L.R.; Pal, H.C.; Elmets, C.A.; Afaq, F. Targeting drivers of melanoma with synthetic small molecules and phytochemicals. Cancer Lett. 2015, 359, 20-35. [CrossRef]

32. Leonida, M.D.; Kumar, I. Bionanomaterials for Skin Regeneration; Springer: Cham, Switzerland, 2016.

33. Nair, H.B.; Sung, B.; Yadav, V.R.; Kannappan, R.; Chaturvedi, M.M.; Aggarwal, B.B. Delivery of antiinflammatory nutraceuticals by nanoparticles for the prevention and treatment of cancer. Biochem. Pharmacol. 2010, 80, 1833-1843. [CrossRef]

34. Siddiqui, I.A.; Mukhtar, H. Nanochemoprevention by bioactive food components: A perspective. Pharm. Res. 2010, 27, 1054-1060. [CrossRef]

35. Fortina, P.; Kricka, L.J.; Surrey, S.; Grodzinski, P. Nanobiotechnology: The promise and reality of new approaches to molecular recognition. Trends Biotechnol. 2005, 23, 168-173. [CrossRef] [PubMed]

36. Choudhury, H.; Gorain, B.; Pandey, M.; Khurana, R.K.; Kesharwani, P. Strategizing biodegradable polymeric nanoparticles to cross the biological barriers for cancer targeting. Int. J. Pharm. 2019, 565, 509-522. [CrossRef] [PubMed]

37. Clemente, N.; Boggio, E.; Gigliotti, L.C.; Raineri, D.; Ferrara, B.; Miglio, G.; Argenziano, M.; Chiocchetti, A.; Cappellano, G.; Trotta, F.; et al. Immunotherapy of experimental melanoma with ICOS-Fc loaded in biocompatible and biodegradable nanoparticles. J. Control. Release 2020, 320, 112-124. [CrossRef]

38. Lee, S.Y.; Koo, J.S.; Yang, M.; Cho, H.-J. Application of temporary agglomeration of chitosan-coated nanoparticles for the treatment of lung metastasis of melanoma. J. Colloid. Interface Sci. 2019, 544, 266-275. [CrossRef]

39. Jain, R. The manufacturing techniques of various drug loaded biodegradable poly(lactide-co-glycolide) (PLGA) devices. Biomaterials 2000, 21, 2475-2490. [CrossRef]

40. Sousa, F.; Cruz, A.; Fonte, P.; Pinto, I.M.; Neves-Petersen, M.T.; Sarmento, B. A new paradigm for antiangiogenic therapy through controlled release of bevacizumab from PLGA nanoparticles. Sci. Rep. 2017, 7, 3736. [CrossRef] [PubMed]

41. Domínguez-Ríos, R.; Sánchez-Ramírez, D.R.; Ruiz-Saray, K.; Oceguera-Basurto, P.E.; Almada, M.; Juárez, J.; Zepeda-Moreno, A.; Del Toro-Arreola, A.; Topete, A.; Daneri-Navarro, A. Cisplatin-loaded PLGA nanoparticles for HER2 targeted ovarian cancer therapy. Colloids Surf. B Biointerfaces 2019, 178, 199-207. [CrossRef] [PubMed]

42. Sims, L.B.; Curry, K.C.; Parupalli, S.; Horner, G.; Frieboes, H.B.; Steinbach-Rankins, J.M. Efficacy of Surface-Modified PLGA Nanoparticles as a Function of Cervical Cancer Type. Pharm. Res. 2019, 36, 1-13. [CrossRef] [PubMed]

43. Fonte, P.; Andrade, F.; Azevedo, C.; Pinto, J.; Seabra, V.; van de Weert, M.; Reis, S.; Sarmento, B. Effect of the Freezing Step in the Stability and Bioactivity of Protein-Loaded PLGA Nanoparticles Upon Lyophilization. Pharm. Res. 2016, 33, 2777-2793. [CrossRef]

44. Fonte, P.; Lino, P.R.; Seabra, V.; Almeida, A.J.; Reis, S.; Sarmento, B. Annealing as a tool for the optimization of lyophilization and ensuring of the stability of protein-loaded PLGA nanoparticles. Int. J. Pharm. 2016, 503, 163-173. [CrossRef] [PubMed]

45. Xin, Y.; Liu, T.; Yang, C. Development of PLGA-lipid nanoparticles with covalently conjugated indocyanine green as a versatile nanoplatform for tumor-targeted imaging and drug delivery. Int. J. Nanomed. 2016, 11, 5807-5821. [CrossRef] [PubMed]

46. Nassir, A.M.; Shahzad, N.; Ibrahim, I.A.A.; Ahmad, I.; Md, S.; Ain, M.R. Resveratrol-loaded PLGA nanoparticles mediated programmed cell death in prostate cancer cells. Saudi Pharm. J. 2018, 26, 876-885. [CrossRef] [PubMed]

47. Zhao, Y.; Huan, M.-1.; Liu, M.; Cheng, Y.; Sun, Y.; Cui, H.; Liu, D.-Z.; Mei, Q.-B.; Zhou, S.-Y. Doxorubicin and resveratrol co-delivery nanoparticle to overcome doxorubicin resistance. Sci. Rep. 2016, 6, 35267. [CrossRef] [PubMed]

48. Tabatabaei Mirakabad, F.S.; Akbarzadeh, A.; Milani, M.; Zarghami, N.; Taheri-Anganeh, M.; Zeighamian, V.; Badrzadeh, F.; Rahmati-Yamchi, M. A Comparison between the cytotoxic effects of pure curcumin and curcumin-loaded PLGA-PEG nanoparticles on the MCF-7 human breast cancer cell line. Artif. Cells Nanomed. Biotechnol. 2016, 44, 423-430. [CrossRef]

49. Singh, M.; Bhatnagar, P.; Mishra, S.; Kumar, P.; Shukla, Y.; Gupta, K.C. PLGA-encapsulated tea polyphenols enhance the chemotherapeutic efficacy of cisplatin against human cancer cells and mice bearing Ehrlich ascites carcinoma. Int. J. Nanomed. 2015, 10, 6789-6809. [CrossRef] [PubMed]

50. Sharma, M.; Sharma, S.; Sharma, V.; Sharma, K.; Yadav, S.K.; Dwivedi, P.; Agrawal, S.; Paliwal, S.K.; Dwivedi, A.K.; Maikhuri, J.P.; et al. Oleanolic-bioenhancer coloaded chitosan modified nanocarriers attenuate breast cancer cells by multimode mechanism and preserve female fertility. Int. J. Biol. Macromol. 2017, 104, 1345-1358. [CrossRef]

51. Das, S.; Das, J.; Samadder, A.; Paul, A.; Khuda-Bukhsh, A.R. Strategic formulation of apigenin-loaded PLGA nanoparticles for intracellular trafficking, DNA targeting and improved therapeutic effects in skin melanoma in vitro. Toxicol. Lett. 2013, 223, 124-138. [CrossRef]

52. Chiu, H.I.; Samad, N.A.; Fang, L.; Lim, V. Cytotoxicity of targeted PLGA nanoparticles: A systematic review. RSC Adv. 2021, 11, 9433-9449. [CrossRef]

53. Ghosh, A.K.; Thapa, R.; Hariani, H.N.; Volyanyuk, M.; Ogle, S.D.; Orloff, K.A.; Ankireddy, S.; Lai, K.; Žiniauskaitė, A.; Stubbs, E.B.; et al. Poly(lactic-co-glycolic acid) nanoparticles encapsulating the prenylated flavonoid, xanthohumol, protect corneal epithelial cells from dry eye disease-associated oxidative stress. Pharmaceutics 2021, 13, 1362. [CrossRef] [PubMed]

54. Barichello, J.M.; Morishita, M.; Takayama, K.; Nagai, T. Encapsulation of hydrophilic and lipophilic drugs in PLGA nanoparticles by the nanoprecipitation method. Drug Dev. Ind. Pharm. 1999, 25, 471-476. [CrossRef] [PubMed]

55. Walden, D.; Kunnimalaiyaan, S.; Sokolowski, K.; Clark, T.G.; Kunnimalaiyaan, M. Antiproliferative and apoptotic effects of xanthohumol in cholangiocarcinoma. Oncotarget 2017, 8, 88069-88078. [CrossRef] [PubMed] 
56. Carvalho, D.O.; Freitas, J.; Nogueira, P.; Henriques, S.N.; Carmo, A.M.; Castro, M.A.; Guido, L.F. Xanthohumol inhibits cell proliferation and induces apoptosis in human thyroid cells. Food Chem. Toxicol. 2018, 121, 450-457.

57. Koo, J.-H.; Kim, H.T.; Yoon, H.-Y.; Kwon, K.-B.; Choi, I.-W.; Jung, S.H.; Kim, H.-U.; Park, B.-H.; Park, J.-W. Effect of xanthohumol on melanogenesis in B16 melanoma cells. Exp. Mol. Med. 2008, 40, 313-319. [CrossRef]

58. Zhang, Y.M.; Shi, X.B.; Xu, B.; Yuan, C.S.; Zheng, W.; Li, G.; Li, J.; Wang, Z.H. Endoplasmic reticulum stress mediated the xanthohumol induced murine melanoma B16-F10 cell death. J. Asian Nat. Prod. Res. 2020, 22, 850-863. [CrossRef]

59. Dorn, C.; Weiss, T.S.; Heilmann, J.; Hellerbrand, C. Xanthohumol, a prenylated chalcone derived from hops, inhibits proliferation, migration and interleukin-8 expression of hepatocellular carcinoma cells. Int. J. Oncol. 2010, 36, 435-441. [CrossRef]

60. Liu, M.; Yin, H.; Qian, X.; Dong, J.; Qian, Z.; Miao, J. Xanthohumol, a prenylated chalcone from hops, inhibits the viability and stemness of doxorubicin-resistant MCF-7/ADR Cells. Molecules 2016, 22, 36. [CrossRef]

61. Denton, A.E.; Roberts, E.W.; Fearon, D.T. Stromal Cells in the Tumor Microenvironment. Adv. Exp. Med. Biol. 2018, 1060, 99-114.

62. Shaul, M.E.; Fridlender, Z.G. Cancer-related circulating and tumor-associated neutrophils-Subtypes, sources and function. FEBS J. 2018, 285, 4316-4342. [CrossRef]

63. Moura, V.; Lacerda, M.; Figueiredo, P.; Corvo, M.L.; Cruz, M.E.; Soares, R.; de Lima, M.C.; Simões, S.; Moreira, J.N. Targeted and intracellular triggered delivery of therapeutics to cancer cells and the tumor microenvironment: Impact on the treatment of breast cancer. Breast Cancer Res. Treat. 2012, 133, 61-73. [CrossRef]

64. Ostuni, R.; Kratochvill, F.; Murray, P.J.; Natoli, G. Macrophages and cancer: From mechanisms to therapeutic implications. Trends Immunol. 2015, 36, 229-239. [CrossRef]

65. Suh, K.S.; Rhee, S.Y.; Kim, Y.S.; Lee, Y.S.; Choi, E.M. Xanthohumol modulates the expression of osteoclast-specific genes during osteoclastogenesis in RAW264.7 cells. Food Chem. Toxicol. 2013, 62, 99-106. [CrossRef] [PubMed]

66. Cho, Y.C.; You, S.K.; Kim, H.J.; Cho, C.W.; Lee, I.S.; Kang, B.Y. Xanthohumol inhibits IL-12 production and reduces chronic allergic contact dermatitis. Int. Immunopharmacol. 2010, 10, 556-561. [CrossRef]

67. Strathmann, J.; Klimo, K.; Sauer, S.W.; Okun, J.G.; Prehn, J.H.; Gerhäuser, C. Xanthohumol-induced transient superoxide anion radical formation triggers cancer cells into apoptosis via a mitochondria-mediated mechanism. FASEB J. 2010, 24, 2938-2950. [CrossRef] [PubMed]

68. Liu, X.; Song, Z.; Bai, J.; Nauwynck, H.; Zhao, Y.; Jiang, P. Xanthohumol inhibits PRRSV proliferation and alleviates oxidative stress induced by PRRSV via the Nrf2-HMOX1 axis. Vet. Res. 2019, 50, 61. [CrossRef] [PubMed]

69. Lima-Fontes, M.; Costa, R.; Rodrigues, I.; Soares, R. Xanthohumol Restores Hepatic Glucolipid Metabolism Balance in Type 1 Diabetic Wistar Rats. J. Agric Food Chem. 2017, 65, 7433-7439. [CrossRef]

70. Costa, R.; Rodrigues, I.; Guardão, L.; Lima, J.Q.; Sousa, E.; Soares, R.; Negrão, R. Modulation of VEGF signaling in a mouse model of diabetes by xanthohumol and 8-prenylnaringenin: Unveiling the angiogenic paradox and metabolism interplay. Mol. Nutr. Food Res. 2017, 61, 1-12. [CrossRef]

71. Tukulula, M.; Hayeshi, R.; Fonteh, P.; Meyer, D.; Ndamase, A.; Madziva, M.T.; Khumalo, V.; Lubuschagne, P.; Naicker, B.; Swai, H.; et al. Curdlan-Conjugated PLGA Nanoparticles Possess Macrophage Stimulant Activity and Drug Delivery Capabilities. Pharm. Res. 2015, 32, 2713-2726. [CrossRef] 